\title{
A Primary Biliary Diffuse Large B-Cell Lymphoma Mimicking Klatskin Tumor in an HIV Patient
}

\author{
Ming Chi Pavankumar Tandra Bassel Jallad Nkem Iroegbu \\ Department of Internal Medicine, Saint Joseph Hospital/University of Illinois at Chicago, USA
}

\section{Keywords}

Non-Hodgkin's lymphoma · HIV · Klatskin tumor

Few cases of primary biliary non-Hodgkin's lymphoma (NHL) mimicking Klatskin tumor have been described in the English literature. We present the first such case in an HIV (human immunodeficiency virus) patient.

A 47-year-old Caucasian male patient presented with jaundice, epigastric discomfort, and weight loss. He had a 20-year history of human immunodeficiency virus (HIV) infection and had been taking emtricitabine/tenofovir/efavirenz

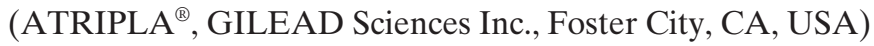
for less than 5 years, with an undetectable viral load, and a lowest recorded CD4 count of 300 cells $/ \mathrm{mm}^{3}$. He had no history of hepatitis or opportunistic infections. The laboratory analyses were consistent with a cholestatic pattern and mild liver parenchymal injury. Acute viral hepatitis and HHV8 serology along with amylase and lipase were within the normal reference range. HIV viral load was 60.00 copies $/ \mathrm{ml}$ (reference range $<48.00$ copies $/ \mathrm{ml}$ ) and absolute CD4 count was 392 cells $/ \mathrm{mm}^{3}$ (reference range 493-1,666 cells $/ \mathrm{mm}^{3}$ ).

Abdominal computed tomography (CT) scan showed a $30 \times 26 \times 15 \mathrm{~mm}$ mass at the confluence of the right and left hepatic main duct with mild intra- and extra-hepatic biliary dilatation (fig. 1) and prominent retroperitoneal lymph nodes (RPLNs). Endoscopic retrograde cholangiopancreatography (ERCP) was attempted to relieve the patient's cholestasis by stent placement. With the patient's HIV status, lymphoma was suspected, and surgical biopsy of the RPLNs was performed. This established the diagnosis of diffuse large B-cell lymphoma (DLBCL) (fig. 2) with positive markers for CD20, CD10, and BCL6. Bone marrow biopsy showed no evidence of tumor involvement.
The patient was continued on ATRIPLA $^{\circledR}$ and finished 5 out of 6 cycles of R-CHOP-21 chemotherapy (rituximab, cyclophosphamide, doxorubicin, vincristine, prednisone), complicated by multiple episodes of neutropenic fever. After the 3rd cycle, a positron emission tomography/CT scan showed no evidence of active mass lesion or lymphadenopathy. After 10 months of follow-up, the patient continues to demonstrate no evidence of disease.

\section{Discussion}

A single hepatic hilar mass poses a diagnostic challenge due to the similar clinical and radiological pictures associated with various potential etiologies [1]. A review of the literature showed only 1 out of 5 cases of Klatskin-like lymphoma being treated with chemotherapy without unnecessary surgical intervention [2]. Klatskin-like non-Hodgkin's lymphoma (NHL), though rare, deserves awareness especially in the HIV population, so that the mainstay treatment, i.e. chemotherapy, can be started early on. Besides, it should also be noted that HIV-related NHL tends to present at an advanced stage and in unusual extranodal sites compared to HIV-negative NHL [3]. Whereas developing NHL while on combined antiretroviral therapy (cART) has emerged as a negative prognostic factor, R-CHOP with the continuation of cART has shown excellent outcomes for DLBCL patients [4].

\section{Disclosure Statement}

The authors have no potential conflicts of interest to disclose.

\section{KARGER \\ Fax +497614520714 \\ Information@Karger.de}

www.karger.com (c) 2011 S. Karger GmbH, Freiburg

0378-584X/11/3410-0555\$38.00/0

Accessible online at:

www.karger.com/onk
Ming Chi, MD, MPH

Department of Internal Medicine

Saint Joseph Hospital/University of Illinois at Chicago

2900 North Shore Drive, Chicago, IL, USA 60657

Tel. +16122071570

chiming-tea@hotmail.com 


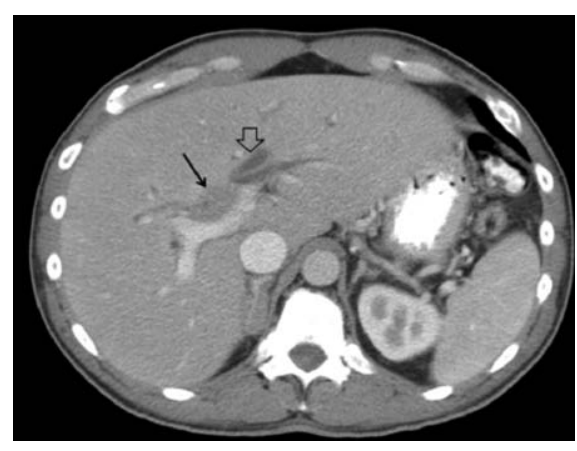

Fig. 1. Abdominal computed tomography scan showing a $30 \times 26 \times 15 \mathrm{~mm}$ mass (thin arrow) with intrahepatic biliary dilatation (thick arrow).

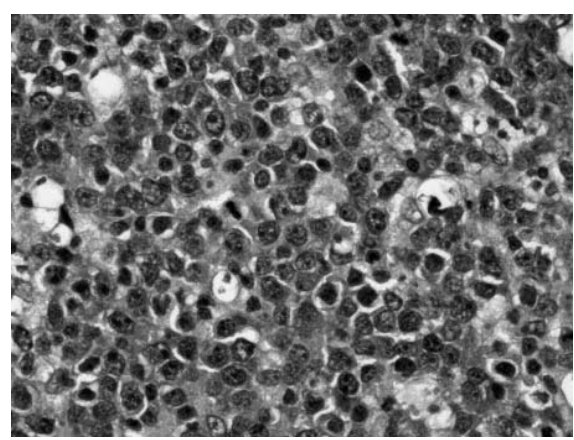

Fig. 2. Hematoxylin and eosin (H\&E) stain demonstrates tumor cells with large hyperchromatic pleomorphic nuclei and prominent central nucleoli $(\times 40)$.

\section{References}

1 Uhlmann D, Wiedmann M, Schmidt F, Kluge R, Tannapfel A, Berr F, Hauss J, Witzigmann H: Management and outcome in patients with Klatskin-mimicking lesions of the biliary tree. J Gastrointest Surg 2006;10:1144-1150.

2 Ghose A, Sethi N, Li G, Chaudhary R: Chemotherapy versus surgery in primary B-cell lymphoma masquerading as Klatskin tumor - a diagnostic and therapeutic dilemma. Am J Ther 2010;Epub ahead of print.

- 3 Tirelli U, Spina M, Gaidano G, Vaccher E, Franceschi S, Carbone A: Epidemiological, biological and clinical features of HIV-related lymphomas in the era of highly active antiretroviral therapy. AIDS 2000;14:1675-1688.

4 Gucalp A, Noy A: Spectrum of HIV lymphoma 2009. Curr Opin Hematol 2010;17:362-367. 